report which has appeared in your journal of Dr. Greenhalgh's speech at the Obstetrical Society, Dec. 3rd, differs materially from that which we heard actually delivered at the Society. Thomas Ballard, M.D., Fellow. Jxo. Lockire, M.D., Visitor. WM. B. OWex, Fellow.

Thos. IR. Pooley, M.D., Visitor.

** The report of the proceedings at the meeting of the Society was official, and furnished to us by one of the hon. secretaries.

\section{OVER-DISTENSION AND RUPTURE OF THE URETHRA.}

To the Editor of Thr LANCET.

Sir,-1My reply to Mr. Thompson's note shall be very brief. I am quite content to take Mr. Thompson's own description of his instrument without requiring any practical test of its ability. Mr. Thompson is perfectly correct. Strictures treated by rapid dilatation do recur so quickly that they recede, as Mr. Thompson shows, four sizes in a day. It is this well.known fact that has induced me for many years to prefer rupture to dilatation. The retention of a catheter in the bladder for the cure of stricture is worse than useless, for it gives rise to irritation without any commensurate benefit. When I first introduced the dilator to the profession, I used it in a large number of cases simply as its name implies. The results were, however, not sufficiently satisfactory to induce me to continue doing so, and I adopted rupture in its stead. This method has succeeded to my entire satisfaction, and so long as it continues to do so I shall not revert to one I have long since tested to the utmost, but have always been disappointed in.

I am, Sir, your obedient servant,

Savile-row, December 17th, 1866. Barnard Holt.

\section{REPRESENTATION OF COLLEGES OF PHYSICIANS AND SURGEONS. \\ To the Editor of THE LANCET.}

SIR,-It is now very generally believed that a measure of reform will be introduced next session of Parliament by the present Ministry. The late Government proposed by the Bill they introduced to give a member to London and the Scotch Universities, and it certainly appeared to me strange that the Colleges of Physicians and Surgeons and the other medical corporations should be entirely overlooked. It is admitted on all sides that the medical profession has not such a share in the legislation of the country as is demanded by the position of its members and the important subjects connected with the profession that are frequently before the House. The profession, as a body, must have great influence in the country, and I feel convinced that if the medical corporations would take the matter up in earnest, and work together with a united action, and if individual members of the profession used their best endeavours to secure the aid of local representatives, it would be found that a very great political influence could be brought to bear on the subject.

I am, Sir, your obedient gervant,

Sunderland, Dec. 10th, 1866 . T. T. Pyle, M.D.

\section{THE MEDICO-CHIRURGICAL TRANSACTIONS. To the Editor of THE LAYYCET.}

Sir,-The volume of Transactions which has just been issued by the Royal Medical and Chirurgical Society is so remarkable in various ways that it merits more than a mere passing word. In the first place, it is much below the usual size (though this would be rather a merit than otherwise, were the contents of good quality), and of the 219 pages of which it consists, more than fifty are occupied by analytical tables illustrative of two of the papers, which are not perhaps of the first importance. The whole number of papers read before the Society during the last session was thirty-three, and of these only seventeen find a place in the Transactions. One of two conclusions is therefore irresistible: either that the remaining sixteen ought not to have been read before the Society; or that the selection of papers for publication is conducted in an arbitrary and therefore unfair manner.
I will say nothing of the papers which have been published, for each of your readers may form his own opinion on the subject by reference to the rolume itself; but with regard to some of the omitted papers I will venture a few remarks. It is hardly to be expected that the society will admit into its Transactions such of the papers as the subsequent discussion proved to be founded on error, or at least wanting confirmation : and thus the treatment of syphilis, either by two-grain doses of chlorate of potash or by the process of so-called syphilization, has not received the endorsement of the Society"s anthority. And again, no one, I imagine, will regret the omission of a remarkable paper on orthopedies by a new method as old as the hills, or on radical cure of hernia, founded on a single case. But there are others, the onission of which has diminished the interest of the volume, and must have, I fear, a deterring effect upon those who wish to bring subjects of interest before the Society. A paper on Pneumonia, by a distinguished provincial physician, even if some of his views do not coincide with those of our leading patholngists, might well have found a place; and so also the record of a case of that rare affection, Myocarditis. If the effects of coffee on the human system are wortby of investigation and record, why not the influence of alcohol" It surely cannot be because the former included the investigation of the urine, which all physicians are accustomed to, whilst the latter involved the tem. perature of the body and the use of the clinical thermometer, a comparatively new instrument !

The surgical world has reason to regret the non-publication of two most interesting cases of urinary calculi, which might well have found a place in the Transactions. One, in which a stone had formed around a nucleus of bone derived from the pelvis, was, I believe, unique; whilst the other was an example of the successful removal of one of the largest mulberry calculi on record. I am at a loss to understand the grounds for their exclusion.

You have recently, in the interests of the Society, urged intending authors to be prompt with their papers, so that they might be read at an early period of the session in extenso. But the volume before me would tend to induce the opposite practice, since it is remarkable that most of the rejected papers occurred early in the session; and thus, of ten papers read in abstract at the last meeting of the session, five are to be found at full length in the Transactions. The standing committee of reference for papers prior to their announcement was a move in a good direction. I would suggest some alteration in the constitution and powers of the committee of reference prior to publication. - Your obedient servant,

Dec. 1866.

A Fellow of the Society.

\section{Bbituarn.}

\section{HEXRY JEAFFRESON, M.D.,}

SENIOR CENSOR OF THE COLLEGE OF PHYAICIAYS, AND SENIOR PHYSICIAN TO ST. BARTHOLOMEW"'S HOSPITAL.

DuRING the earlier days of last and the closing days of the preceding week no observant person passed through Finsburysquare, or its chief adjacent thoroughfares, without seeing, in the darkened windows of that centre of medical life, an evidence of the regret felt by the profession for the sudden and premature loss of one of its most distinguished and popular members. But the quarter thus covered with visible gloom for the abrupt decease of a familiar and beloved friend was only the centre of a wide circle that experienced a sense of domestic bereavement and personal misfortune when it was announced that, in spite of the skill and assiduous care of the medical friends who surrounded his bed, the kindly and skilful senior physician of st. Bartholomew's Hospital had succumbed to typhus ferer in the fifty-seventh year of his age. Since the calamitous end of William Baly struck the country with consternation, no death within the ranks of the profession has created deeper sensation in general society, or inflicted hearier loss on our oldest medical school. And now that we have mastered the first sharpness of our private sorrow, it is with no common feelings of dejection that we estimate the loss which the public has sustained, and cast up the sum of his rarious endowments and fine qualities. 